\title{
Almost stability of the Mann type iteration method with error term involving strictly hemicontractive mappings in smooth Banach spaces
}

\author{
Nawab Hussain ${ }^{1}$, Arif Rafiq² ${ }^{2}{\text { Ljubomir B } \text { Ciric }^{3} \text { and Saleh Al-Mezel }}^{1 *}$
}

${ }^{*}$ Correspondence:

salmezel@kau.edu.sa

${ }^{1}$ Department of Mathematics, King

Abdulaziz University, P.O. Box 80203

Jeddah, 21589, Saudi Arabia

Full list of author information is

available at the end of the article

\begin{abstract}
Let $K$ be a nonempty closed bounded convex subset of an arbitrary smooth Banach space $X$ and $T: K \rightarrow K$ be a continuous strictly hemicontractive mapping. Under some conditions, we obtain that the Mann iteration method with error term converges strongly to a unique fixed point of $T$ and is almost $T$-stable on $K$. As an application of our results, we establish strong convergence of a multi-step iteration process.
\end{abstract}

Keywords: Mann iteration method with error term; strictly hemicontractive operators; strongly pseudocontractive operators; local strongly pseudocontractive operators; continuous mappings; Lipschitz mappings; smooth Banach spaces

\section{Introduction}

Chidume [1] established that the Mann iteration sequence converges strongly to the unique fixed point of $T$ in case $T$ is a Lipschitz strongly pseudo-contractive mapping from a bounded closed convex subset of $L_{p}\left(\right.$ or $\left.l_{p}\right)$ into itself. Schu [2] generalized the result in [1] to both uniformly continuous strongly pseudo-contractive mappings and real smooth Banach spaces. Park [3] extended the result in [1] to both strongly pseudocontractive mappings and certain smooth Banach spaces. Rhoades [4] proved that the Mann and Ishikawa iteration methods may exhibit different behavior for different classes of nonlinear mappings. Harder and Hicks $[5,6]$ revealed the importance of investigating the stability of various iteration procedures for various classes of nonlinear mappings. Harder [7] established applications of stability results to first-order differential equations. Afterwords, several generalizations have been made in various directions (see, for example, [2, 4, 8-21].

Let $K$ be a nonempty closed bounded convex subset of an arbitrary smooth Banach space $X$ and $T: K \rightarrow K$ be a continuous strictly hemicontractive mapping. Under some conditions, we obtain that the Mann iteration method with error term converges strongly to a unique fixed point of $T$ and is almost $T$-stable on $K$. As an application, we shall also establish strong convergence of a multi-step iteration process. The results presented here generalize the corresponding results in $[2-4,10,11,22]$.

( 2012 Hussain et al.; licensee Springer. This is an Open Access article distributed under the terms of the Creative Commons Attribution License (http://creativecommons.org/licenses/by/2.0), which permits unrestricted use, distribution, and reproduction in any medium, provided the original work is properly cited. 


\section{Preliminaries}

Let $K$ be a nonempty subset of an arbitrary Banach space $X$ and $X^{*}$ be its dual space. The symbols $D(T), R(T)$ and $F(T)$ stand for the domain, the range and the set of fixed points of $T: X \rightarrow X$ respectively ( $x$ is called a fixed point of $T$ iff $T(x)=x$ ). We denote by $J$ the normalized duality mapping from $X$ to $2^{X^{*}}$ defined by

$$
J(x)=\left\{f^{*} \in X^{*}:\left\langle x, f^{*}\right\rangle=\|x\|^{2}=\left\|f^{*}\right\|^{2}\right\} .
$$

Let $T$ be a self-mapping of $K$.

Definition 1 The mapping $T$ is called Lipshitzian if there exists $L>0$ such that

$$
\|T x-T y\| \leq L\|x-y\|
$$

for all $x, y \in K$. If $L=1$, then $T$ is called non-expansive and if $0 \leq L<1, T$ is called contraction.

Definition $2[10,22]$

1. The mapping $T$ is said to be pseudocontractive if the inequality

$$
\|x-y\| \leq\|x-y+t[(I-T) x-(I-T) y]\|
$$

holds for each $x, y \in K$ and for all $t>0$.

2. $T$ is said to be strongly pseudocontractive if there exists $t>1$ such that

$$
\|x-y\| \leq\|(1+r)(x-y)-r t(T x-T y)\|
$$

for all $x, y \in D(T)$ and $r>0$.

3. $T$ is said to be local strongly pseudocontractive if for each $x \in D(T)$, there exists $t_{x}>1$ such that

$$
\|x-y\| \leq\left\|(1+r)(x-y)-r t_{x}(T x-T y)\right\|
$$

for all $y \in D(T)$ and $r>0$.

4. $T$ is said to be strictly hemicontractive if $F(T) \neq \emptyset$ and if there exists $t>1$ such that

$$
\|x-q\| \leq\|(1+r)(x-q)-r t(T x-q)\|
$$

for all $x \in D(T), q \in F(T)$ and $r>0$.

Clearly, each strongly pseudocontractive operator is local strongly pseudocontractive.

Definition 3 [5-7] Let $K$ be a nonempty convex subset of $X$ and $T: K \rightarrow K$ be an operator. Assume that $x_{o} \in K$ and $x_{n+1}=f\left(T, x_{n}\right)$ defines an iteration scheme which produces a sequence $\left\{x_{n}\right\}_{n=0}^{\infty} \subset K$. Suppose, furthermore, that $\left\{x_{n}\right\}_{n=0}^{\infty}$ converges strongly to $q \in F(T) \neq \emptyset$. Let $\left\{y_{n}\right\}_{n=0}^{\infty}$ be any bounded sequence in $K$ and put $\varepsilon_{n}=\left\|y_{n+1}-f\left(T, y_{n}\right)\right\|$. 
(1) The iteration scheme $\left\{x_{n}\right\}_{n=0}^{\infty}$ defined by $x_{n+1}=f\left(T, x_{n}\right)$ is said to be $T$-stable on $K$ if $\lim _{n \rightarrow \infty} \varepsilon_{n}=0$ implies that $\lim _{n \rightarrow \infty} y_{n}=q$.

(2) The iteration scheme $\left\{x_{n}\right\}_{n=0}^{\infty}$ defined by $x_{n+1}=f\left(T, x_{n}\right)$ is said to be almost $T$-stable on $K$ if $\sum_{n=0}^{\infty} \varepsilon_{n}<\infty$ implies that $\lim _{n \rightarrow \infty} y_{n}=q$.

It is easy to verify that an iteration scheme $\left\{x_{n}\right\}_{n=0}^{\infty}$ which is $T$-stable on $K$ is almost $T$-stable on $K$.

Lemma 4 [3] Let $X$ be a smooth Banach space. Suppose one of the following holds:

(1) $J$ is uniformly continuous on any bounded subsets of $X$,

(2) $\langle x-y, j(x)-j(y)\rangle \leq\|x-y\|^{2}$ for all $x, y$ in $X$,

(3) for any bounded subset $D$ of $X$, there is a $c:[0, \infty) \rightarrow[0, \infty)$ such that

$$
\operatorname{Re}\langle x-y, j(x)-j(y)\rangle \leq c(\|x-y\|)
$$

for all $x, y \in D$, where $c$ satisfies

$$
\lim _{t \rightarrow 0^{+}} \frac{c(t)}{t}=0
$$

Then for any $\epsilon>0$ and any bounded subset $K$, there exists $\delta>0$ such that

$$
\|s x+(1-s) y\|^{2} \leq(1-2 s)\|y\|^{2}+2 s \operatorname{Re}(x, j(y))+2 s \epsilon
$$

for all $x, y \in K$ and $s \in[0, \delta]$.

Lemma 5 [10] Let $T: D(T) \subseteq X \rightarrow X$ be an operator with $F(T) \neq \varphi$. Then $T$ is strictly hemicontractive if and only if there exists $t>1$ such that for all $x \in D(T)$ and $q \in F(T)$, there exists $j(x-q) \in J(x-q)$ satisfying

$$
\operatorname{Re}\langle x-T x, j(x-q)\rangle \geq\left(1-\frac{1}{t}\right)\|x-q\|^{2} .
$$

Lemma 6 [4] Let $X$ be an arbitrary normed linear space and $T: D(T) \subseteq X \rightarrow X$ be an operator.

(1) If $T$ is a local strongly pseudocontractive operator and $F(T) \neq \emptyset$, then $F(T)$ is a singleton and $T$ is strictly hemicontractive.

(2) If $T$ is strictly hemicontractive, then $F(T)$ is a singleton.

\section{Main results}

We now prove our main results.

Lemma 7 Let $\left\{\alpha_{n}\right\}_{n=0}^{\infty},\left\{\beta_{n}\right\}_{n=0}^{\infty}$ and $\left\{\gamma_{n}\right\}_{n=0}^{\infty}$ be nonnegative real sequences, and let $\epsilon^{\prime}>0$ be a constant satisfying

$$
\beta_{n+1} \leq\left(1-\alpha_{n}^{l}\right) \beta_{n}+\epsilon^{\prime} \alpha_{n}+\gamma_{n} ; \quad l \geq 1, n \geq 0,
$$

where $\sum_{n=0}^{\infty} \alpha_{n}^{l}=\infty, \alpha_{n} \leq 1$ for all $n \geq 0$ and $\sum_{n=0}^{\infty} \gamma_{n}<\infty$. Then, $\lim _{n \rightarrow \infty} \sup \beta_{n} \leq \epsilon^{\prime}$. 
Proof By a straightforward argument, for $n \geq k \geq 0$,

$$
\beta_{n+1} \leq \beta_{k} \prod_{j=k}^{n}\left(1-\alpha_{j}^{l}\right)+\epsilon^{\prime} \sum_{j=k}^{n} \alpha_{j} \prod_{i=j+1}^{n}\left(1-\alpha_{i}^{l}\right)+\sum_{j=k}^{n} \gamma_{j} \prod_{i=j+1}^{n}\left(1-\alpha_{i}^{l}\right),
$$

where we put $\prod_{i=n+1}^{n}\left(1-\alpha_{i}^{l}\right)=1$. Note that $\sum_{j=k}^{n} \alpha_{j} \prod_{i=j+1}^{n}\left(1-\alpha_{i}^{l}\right) \leq 1$. It follows from (3.1) that

$$
\beta_{n+1} \leq \exp \left(-\sum_{j=k}^{n} \alpha_{j}^{l}\right) \beta_{k}+\epsilon^{\prime}+\sum_{j=k}^{n} \gamma_{j}
$$

For a given $\delta>0$, there exists a positive integer $k$ such that $\sum_{j=k}^{\infty} \gamma_{j}<\delta$. Thus (3.2) ensures that

$$
\lim _{n \rightarrow \infty} \sup \beta_{n} \leq \epsilon^{\prime}+\delta
$$

Letting $\delta \rightarrow 0^{+}$yields $\lim _{n \rightarrow \infty} \sup \beta_{n} \leq \epsilon^{\prime}$.

\section{Remark 8}

(i) If $\gamma_{n}=0$ for each $n \geq 0$, then Lemma 7 reduces to Lemma 1 of Park [3].

(ii) If $l=1$, then Lemma 7 reduces to Lemma 2.1 of Liu et al. [4].

Theorem 9 Let Xbe a smooth Banach space satisfying any one of the Axioms (1)-(3) of Lemma 4. Let $K$ be a nonempty closed bounded convex subset of $X$ and $T: K \rightarrow K$ be a continuous strictly hemicontractive mapping. Suppose that $\left\{u_{n}\right\}_{n=0}^{\infty}$ is an arbitrary sequence in $K$ and $\left\{a_{n}^{\prime}\right\}_{n=0}^{\infty},\left\{b_{n}^{\prime}\right\}_{n=0}^{\infty}$ and $\left\{c_{n}^{\prime}\right\}_{n=0}^{\infty}$ are any sequences in $[0,1]$ satisfying conditions (i) $a_{n}^{\prime}+b_{n}^{\prime}+c_{n}^{\prime}=1$, (ii) $c_{n}^{\prime}=o\left(b_{n}^{\prime}\right)$, (iii) $\lim _{n \rightarrow \infty} b_{n}^{\prime}=0$ and (iv) $\sum_{n=0}^{\infty} b_{n}^{\prime}=\infty$.

For a sequence $\left\{v_{n}\right\}_{n=0}^{\infty}$ in $K$, suppose that $\left\{x_{n}\right\}_{n=0}^{\infty}$ is the sequence generated from an arbitrary $x_{0} \in K$ by

$$
x_{n+1}=a_{n}^{\prime} x_{n}+b_{n}^{\prime} T v_{n}+c_{n}^{\prime} u_{n}, \quad n \geq 0,
$$

and satisfying $\lim _{n \rightarrow \infty}\left\|v_{n}-x_{n}\right\|=0$.

Let $\left\{y_{n}\right\}_{n=0}^{\infty}$ be any sequence in $K$ and define $\left\{\varepsilon_{n}\right\}_{n=0}^{\infty}$ by

$$
\varepsilon_{n}=\left\|y_{n+1}-p_{n}\right\|, \quad n \geq 0,
$$

where $p_{n}=a_{n}^{\prime} y_{n}+b_{n}^{\prime} T v_{n}+c_{n}^{\prime} u_{n}$, such that $\lim _{n \rightarrow \infty}\left\|v_{n}-y_{n}\right\|=0$.

Then

(a) the sequence $\left\{x_{n}\right\}_{n=0}^{\infty}$ converges strongly to a unique fixed point $q$ of $T$,

(b) $\sum_{n=0}^{\infty} \varepsilon_{n}<\infty$ implies that $\lim _{n \rightarrow \infty} y_{n}=q$, so that $\left\{x_{n}\right\}_{n=0}^{\infty}$ is almost $T$-stable on $K$,

(c) $\lim _{n \rightarrow \infty} y_{n}=q$ implies that $\lim _{n \rightarrow \infty} \varepsilon_{n}=0$.

Proof From (ii), we have $c_{n}^{\prime}=t_{n} b_{n}^{\prime}$, where $t_{n} \rightarrow 0$ as $n \rightarrow \infty$.

It follows from Lemma 6 that $F(T)$ is a singleton. That is, $F(T)=\{q\}$ for some $q \in K$. 
Set $M=1+\operatorname{diam} K$. For all $n \geq 0$, it is easy to verify that

$$
\begin{aligned}
M= & \sup _{n \geq 0}\left\|x_{n}-q\right\|+\sup _{n \geq 0}\left\|T v_{n}-q\right\|+\sup _{n \geq 0}\left\|u_{n}-q\right\| \\
& +\sup _{n \geq 0}\left\{\left\|p_{n}-q\right\|\right\}+\sup _{n \geq 0}\left\|y_{n}-q\right\| .
\end{aligned}
$$

For given any $\epsilon>0$ and the bounded subset $K$, there exists a $\delta>0$ satisfying (2.6). Note that (ii), (iii), $\lim _{n \rightarrow \infty}\left\|v_{n}-x_{n}\right\|=0$ and the continuity of $T$ ensure that there exists an $N$ such that

$$
b_{n}^{\prime}<\min \left\{\delta, \frac{1}{2(1-k)}\right\}, \quad t_{n} \leq \frac{\epsilon}{16 M^{2}}, \quad\left\|T v_{n}-T x_{n}\right\| \leq \frac{\epsilon}{4 M}, \quad n \geq N
$$

where $k=\frac{1}{t}$ and $t$ satisfies (2.7). Using (3.3) and Lemma 4, we infer that

$$
\begin{aligned}
\left\|x_{n+1}-q\right\|^{2}= & \left\|\left(1-b_{n}^{\prime}\right)\left(x_{n}-q\right)+b_{n}^{\prime}\left(T v_{n}-q\right)+c_{n}^{\prime}\left(u_{n}-x_{n}\right)\right\|^{2} \\
\leq & \left(\left\|\left(1-b_{n}^{\prime}\right)\left(x_{n}-q\right)+b_{n}^{\prime}\left(T v_{n}-q\right)\right\|+2 M c_{n}^{\prime}\right)^{2} \\
\leq & \left\|\left(1-b_{n}^{\prime}\right)\left(x_{n}-q\right)+b_{n}^{\prime}\left(T v_{n}-q\right)\right\|^{2}+8 M^{2} c_{n}^{\prime} \\
\leq & \left(1-2 b_{n}^{\prime}\right)\left\|x_{n}-q\right\|^{2}+2 b_{n}^{\prime} \operatorname{Re}\left(T v_{n}-q, j\left(x_{n}-q\right)\right)+2 \epsilon b_{n}^{\prime}+8 M^{2} c_{n}^{\prime} \\
= & \left(1-2 b_{n}^{\prime}\right)\left\|x_{n}-q\right\|^{2}+2 b_{n}^{\prime} \operatorname{Re}\left(T x_{n}-q, j\left(x_{n}-q\right)\right) \\
& +2 b_{n}^{\prime} \operatorname{Re}\left(T v_{n}-T x_{n}, j\left(x_{n}-q\right)\right)+2 \epsilon b_{n}^{\prime}+8 M^{2} c_{n}^{\prime} \\
\leq & \left(1-2 b_{n}^{\prime}\right)\left\|x_{n}-q\right\|^{2}+2 k b_{n}^{\prime}\left\|x_{n}-q\right\|^{2} \\
& +2 b_{n}^{\prime}\left\|T v_{n}-T x_{n}\right\|\left\|x_{n}-q\right\|+2 \epsilon b_{n}^{\prime}+8 M^{2} c_{n}^{\prime} \\
\leq & \left(1-2(1-k) b_{n}^{\prime}\right)\left\|x_{n}-q\right\|^{2} \\
& +2 M b_{n}^{\prime}\left\|T v_{n}-T x_{n}\right\|+2 \epsilon b_{n}^{\prime}+8 M^{2} c_{n}^{\prime} \\
\leq & \left(1-2(1-k) b_{n}^{\prime}\right)\left\|x_{n}-q\right\|^{2}+3 \epsilon b_{n}^{\prime},
\end{aligned}
$$

for all $n \geq N$.

Put

$$
\begin{aligned}
& \beta_{n}=\left\|x_{n}-q\right\|, \\
& \alpha_{n}=2(1-k) b_{n}^{\prime}, \\
& \epsilon^{\prime}=\frac{3 \epsilon}{2(1-k)}, \\
& \gamma_{n}=0,
\end{aligned}
$$

we have from (3.7)

$$
\beta_{n+1} \leq\left(1-\alpha_{n}\right) \beta_{n}+\epsilon^{\prime} \alpha_{n}+\gamma_{n}, \quad n \geq 0
$$

Observe that $\sum_{n=0}^{\infty} \alpha_{n}=\infty, \alpha_{n}<1$ for all $n \geq 0$. It follows from Lemma 7 that

$$
\lim _{n \rightarrow \infty} \sup \left\|x_{n}-q\right\|^{2} \leq \epsilon^{\prime}
$$


Letting $\epsilon^{\prime} \rightarrow 0^{+}$, we obtain that $\lim _{n \rightarrow \infty}$ sup $\left\|x_{n}-q\right\|^{2}=0$, which implies that $x_{n} \rightarrow q$ as $n \rightarrow \infty$

On the same lines, we obtain

$$
\begin{aligned}
\left\|p_{n}-q\right\|^{2}= & \left\|\left(1-b_{n}^{\prime}\right)\left(y_{n}-q\right)+b_{n}^{\prime}\left(T v_{n}-q\right)+c_{n}^{\prime}\left(u_{n}-y_{n}\right)\right\|^{2} \\
\leq & \left(\left\|\left(1-b_{n}^{\prime}\right)\left(y_{n}-q\right)+b_{n}^{\prime}\left(T v_{n}-q\right)\right\|+2 M c_{n}^{\prime}\right)^{2} \\
\leq & \left\|\left(1-b_{n}^{\prime}\right)\left(y_{n}-q\right)+b_{n}^{\prime}\left(T v_{n}-q\right)\right\|^{2}+8 M^{2} c_{n}^{\prime} \\
\leq & \left(1-2 b_{n}^{\prime}\right)\left\|y_{n}-q\right\|^{2}+2 b_{n}^{\prime} \operatorname{Re}\left(T v_{n}-q, j\left(y_{n}-q\right)\right)+2 \epsilon b_{n}^{\prime}+8 M^{2} c_{n}^{\prime} \\
= & \left(1-2 b_{n}^{\prime}\right)\left\|y_{n}-q\right\|^{2}+2 b_{n}^{\prime} \operatorname{Re}\left(T y_{n}-q, j\left(y_{n}-q\right)\right) \\
& +2 b_{n}^{\prime} \operatorname{Re}\left(T v_{n}-T y_{n}, j\left(y_{n}-q\right)\right)+2 \epsilon b_{n}^{\prime}+8 M^{2} c_{n}^{\prime} \\
\leq & \left(1-2 b_{n}^{\prime}\right)\left\|y_{n}-q\right\|^{2}+2 k b_{n}^{\prime}\left\|y_{n}-q\right\|^{2} \\
& +2 b_{n}^{\prime}\left\|T v_{n}-T y_{n}\right\|\left\|y_{n}-q\right\|+2 \epsilon b_{n}^{\prime}+8 M^{2} c_{n}^{\prime} \\
\leq & \left(1-2(1-k) b_{n}^{\prime}\right)\left\|y_{n}-q\right\|^{2} \\
& +2 M b_{n}^{\prime}\left\|T v_{n}-T y_{n}\right\|+2 \epsilon b_{n}^{\prime}+8 M^{2} c_{n}^{\prime} \\
\leq & \left(1-2(1-k) b_{n}^{\prime}\right)\left\|y_{n}-q\right\|^{2}+3 \epsilon b_{n}^{\prime},
\end{aligned}
$$

for all $n \geq N$.

Suppose that $\sum_{n=0}^{\infty} \varepsilon_{n}<\infty$. In view of (3.4) and (3.8), we infer that

$$
\begin{aligned}
\left\|y_{n+1}-q\right\|^{2} & \leq\left(\left\|y_{n+1}-p_{n}\right\|+\left\|p_{n}-q\right\|\right)^{2} \\
& \leq\left\|p_{n}-q\right\|^{2}+3 M \varepsilon_{n} \\
& \leq\left[1-2 b_{n}^{\prime}(1-k)\right]\left\|y_{n}-q\right\|^{2}+3 \epsilon b_{n}^{\prime}+3 M \varepsilon_{n},
\end{aligned}
$$

for all $n \geq N$.

Now, put

$$
\begin{aligned}
& \beta_{n}=\left\|y_{n}-q\right\|, \\
& \alpha_{n}=2(1-k) b_{n}^{\prime}, \\
& \epsilon^{\prime}=\frac{3 \epsilon}{2(1-k)}, \\
& \gamma_{n}=3 M \varepsilon_{n},
\end{aligned}
$$

and we have from (3.9)

$$
\beta_{n+1} \leq\left(1-\alpha_{n}\right) \beta_{n}+\epsilon^{\prime} \alpha_{n}+\gamma_{n}, \quad n \geq 0 .
$$

Observe that $\sum_{n=0}^{\infty} \alpha_{n}=\infty, \alpha_{n}<1$ and $\sum_{n=0}^{\infty} \gamma_{n}<\infty$ for all $n \geq 0$. It follows from Lemma 7 that

$$
\lim _{n \rightarrow \infty} \sup \left\|y_{n}-q\right\|^{2} \leq \epsilon^{\prime}
$$


Letting $\epsilon^{\prime} \rightarrow 0^{+}$, we obtain that $\lim _{n \rightarrow \infty} \sup \left\|y_{n}-q\right\|^{2}=0$, which implies that $y_{n} \rightarrow q$ as $n \rightarrow \infty$

Conversely, suppose that $\lim _{n \rightarrow \infty} y_{n}=q$, then (iii) and (3.8) imply that

$$
\begin{aligned}
\varepsilon_{n} & \leq\left\|y_{n+1}-q\right\|+\left\|p_{n}-q\right\| \\
& \leq\left\|y_{n+1}-q\right\|+\left[\left[1-2(1-k) b_{n}^{\prime}\right]\left\|y_{n}-q\right\|^{2}+3 \epsilon b_{n}^{\prime}\right]^{\frac{1}{2}} \\
& \rightarrow 0
\end{aligned}
$$

as $n \rightarrow \infty$, that is, $\varepsilon_{n} \rightarrow 0$ as $n \rightarrow \infty$.

Using the methods of the proof of Theorem 9, we can easily prove the following.

Theorem 10 Let $X, K, T$ and $\left\{u_{n}\right\}_{n=0}^{\infty}$, be as in Theorem 9. Suppose that $\left\{a_{n}^{\prime}\right\}_{n=0}^{\infty},\left\{b_{n}^{\prime}\right\}_{n=0}^{\infty}$ and $\left\{c_{n}^{\prime}\right\}_{n=0}^{\infty}$ are sequences in $[0,1]$ satisfying conditions (i), (iii)-(iv) and

$$
\sum_{n=0}^{\infty} c_{n}^{\prime}<\infty .
$$

If $\left\{x_{n}\right\}_{n=0}^{\infty},\left\{v_{n}\right\}_{n=0}^{\infty},\left\{y_{n}\right\}_{n=0}^{\infty},\left\{p_{n}\right\}_{n=0}^{\infty}$ and $\left\{\varepsilon_{n}\right\}_{n=0}^{\infty}$ are as in Theorem 9 , then the conclusions of Theorem 9 hold.

Corollary 11 Let $X$ be a smooth Banach space satisfying any one of the Axioms (1)-(3) of Lemma 4. Let $K$ be a nonempty closed bounded convex subset of $X$ and $T: K \rightarrow K$ be a Lipschitz strictly hemicontractive mapping. Suppose that $\left\{u_{n}\right\}_{n=0}^{\infty}$ is an arbitrary sequence in $K$ and $\left\{a_{n}^{\prime}\right\}_{n=0}^{\infty},\left\{b_{n}^{\prime}\right\}_{n=0}^{\infty}$ and $\left\{c_{n}^{\prime}\right\}_{n=0}^{\infty}$ are any sequences in $[0,1]$ satisfying conditions (i) $a_{n}^{\prime}+b_{n}^{\prime}+c_{n}^{\prime}=1$, (ii) $c_{n}^{\prime}=o\left(b_{n}^{\prime}\right)$, (iii) $\lim _{n \rightarrow \infty} b_{n}^{\prime}=0$ and (iv) $\sum_{n=0}^{\infty} b_{n}^{\prime}=\infty$.

For a sequence $\left\{v_{n}\right\}_{n=0}^{\infty}$ in $K$, suppose that $\left\{x_{n}\right\}_{n=0}^{\infty}$ is the sequence generated from an arbitrary $x_{0} \in K$ by

$$
x_{n+1}=a_{n}^{\prime} x_{n}+b_{n}^{\prime} T v_{n}+c_{n}^{\prime} u_{n}, \quad n \geq 0,
$$

and satisfying $\lim _{n \rightarrow \infty}\left\|v_{n}-x_{n}\right\|=0$.

Let $\left\{y_{n}\right\}_{n=0}^{\infty}$ be any sequence in $K$ and define $\left\{\varepsilon_{n}\right\}_{n=0}^{\infty}$ by

$$
\varepsilon_{n}=\left\|y_{n+1}-p_{n}\right\|, \quad n \geq 0,
$$

where $p_{n}=a_{n}^{\prime} y_{n}+b_{n}^{\prime} T v_{n}+c_{n}^{\prime} u_{n}$, such that $\lim _{n \rightarrow \infty}\left\|v_{n}-y_{n}\right\|=0$.

Then

(a) the sequence $\left\{x_{n}\right\}_{n=0}^{\infty}$ converges strongly to a unique fixed point $q$ of $T$,

(b) $\sum_{n=0}^{\infty} \varepsilon_{n}<\infty$ implies that $\lim _{n \rightarrow \infty} y_{n}=q$, so that $\left\{x_{n}\right\}_{n=0}^{\infty}$ is almost $T$-stable on $K$,

(c) $\lim _{n \rightarrow \infty} y_{n}=q$ implies that $\lim _{n \rightarrow \infty} \varepsilon_{n}=0$.

Corollary 12 Let $X, K, T$ and $\left\{u_{n}\right\}_{n=0}^{\infty}$ be as in Corollary 11. Suppose that $\left\{a_{n}^{\prime}\right\}_{n=0}^{\infty},\left\{b_{n}^{\prime}\right\}_{n=0}^{\infty}$ and $\left\{c_{n}^{\prime}\right\}_{n=0}^{\infty}$ are sequences in $[0,1]$ satisfying conditions (i), (iii)-(iv) and

$$
\sum_{n=0}^{\infty} c_{n}^{\prime}<\infty
$$


If $\left\{x_{n}\right\}_{n=0}^{\infty},\left\{v_{n}\right\}_{n=0}^{\infty},\left\{y_{n}\right\}_{n=0}^{\infty},\left\{p_{n}\right\}_{n=0}^{\infty}$ and $\left\{\varepsilon_{n}\right\}_{n=0}^{\infty}$ are as in Corollary 11, then the conclusions of Corollary 11 hold.

Corollary 13 Let $X$ be a smooth Banach space satisfying any one of the Axioms (1)-(3) of Lemma 4. Let $K$ be a nonempty closed bounded convex subset of $X$ and $T: K \rightarrow K$ be a continuous strictly hemicontractive mapping. Suppose that $\left\{\alpha_{n}\right\}_{n=0}^{\infty}$ is a sequence in $[0,1]$ satisfying conditions (i) $\lim _{n \rightarrow \infty} \alpha_{n}=0$ and (ii) $\sum_{n=0}^{\infty} \alpha_{n}=\infty$.

For a sequence $\left\{v_{n}\right\}_{n=0}^{\infty}$ in $K$, suppose that $\left\{x_{n}\right\}_{n=0}^{\infty}$ is the sequence generated from an arbitrary $x_{0} \in K$ by

$$
x_{n+1}=\alpha_{n} x_{n}+\left(1-\alpha_{n}\right) T v_{n}, \quad n \geq 0,
$$

and satisfying $\lim _{n \rightarrow \infty}\left\|v_{n}-x_{n}\right\|=0$.

Let $\left\{y_{n}\right\}_{n=0}^{\infty}$ be any sequence in $K$ and define $\left\{\varepsilon_{n}\right\}_{n=0}^{\infty}$ by

$$
\varepsilon_{n}=\left\|y_{n+1}-p_{n}\right\|, \quad n \geq 0
$$

where $p_{n}=\alpha_{n} y_{n}+\left(1-\alpha_{n}\right) T v_{n}$, such that $\lim _{n \rightarrow \infty}\left\|v_{n}-y_{n}\right\|=0$.

Then

(a) the sequence $\left\{x_{n}\right\}_{n=0}^{\infty}$ converges strongly to a unique fixed point $q$ of $T$,

(b) $\sum_{n=0}^{\infty} \varepsilon_{n}<\infty$ implies that $\lim _{n \rightarrow \infty} y_{n}=q$, so that $\left\{x_{n}\right\}_{n=0}^{\infty}$ is almost $T$-stable on $K$,

(c) $\lim _{n \rightarrow \infty} y_{n}=q$ implies that $\lim _{n \rightarrow \infty} \varepsilon_{n}=0$.

Corollary 14 Let $X$ be a smooth Banach space satisfying any one of the Axioms (1)-(3) of Lemma 4. Let $K$ be a nonempty closed bounded convex subset of $X$ and $T: K \rightarrow K$ be a Lipschitz strictly hemicontractive mapping. Suppose that $\left\{\alpha_{n}\right\}_{n=0}^{\infty}$ is a sequence in $[0,1]$ satisfying conditions (i) $\lim _{n \rightarrow \infty} \alpha_{n}=0$ and (ii) $\sum_{n=0}^{\infty} \alpha_{n}=\infty$.

For a sequence $\left\{v_{n}\right\}_{n=0}^{\infty}$ in $K$, suppose that $\left\{x_{n}\right\}_{n=0}^{\infty}$ is the sequence generated from an arbitrary $x_{0} \in K$ by

$$
x_{n+1}=\alpha_{n} x_{n}+\left(1-\alpha_{n}\right) T v_{n}, \quad n \geq 0,
$$

and satisfying $\lim _{n \rightarrow \infty}\left\|v_{n}-x_{n}\right\|=0$.

Let $\left\{y_{n}\right\}_{n=0}^{\infty}$ be any sequence in $K$ and define $\left\{\varepsilon_{n}\right\}_{n=0}^{\infty}$ by

$$
\varepsilon_{n}=\left\|y_{n+1}-p_{n}\right\|, \quad n \geq 0,
$$

where $p_{n}=\alpha_{n} y_{n}+\left(1-\alpha_{n}\right) T v_{n}$, such that $\lim _{n \rightarrow \infty}\left\|v_{n}-y_{n}\right\|=0$.

Then

(a) the sequence $\left\{x_{n}\right\}_{n=0}^{\infty}$ converges strongly to a unique fixed point $q$ of $T$,

(b) $\sum_{n=0}^{\infty} \varepsilon_{n}<\infty$ implies that $\lim _{n \rightarrow \infty} y_{n}=q$, so that $\left\{x_{n}\right\}_{n=0}^{\infty}$ is almost T-stable on $K$,

(c) $\lim _{n \rightarrow \infty} y_{n}=q$ implies that $\lim _{n \rightarrow \infty} \varepsilon_{n}=0$.

\section{Applications to a multi-step iteration process}

Khan et al. [23] have introduced and studied a multi-step iteration process for a finite family of selfmappings. We now introduce a modified multi-step process as follows:

Let $K$ be a nonempty closed convex subset of a real normed space $E$ and $T_{1}, T_{2}, \ldots, T_{p}$ : $K \rightarrow K(p \geq 2)$ be a family of selfmappings. 
Algorithm 1 For a given $x_{0} \in K$, compute the sequence $\left\{x_{n}\right\}_{n \geq 0}$ by the iteration process of arbitrary fixed order $p \geq 2$,

$$
\begin{aligned}
& x_{n+1}=\left(1-\alpha_{n}\right) x_{n}+\alpha_{n} T_{1} y_{n}^{1}, \\
& y_{n}^{i}=\left(1-\beta_{n}^{i}\right) x_{n}+\beta_{n}^{i} T_{i+1} y_{n}^{i+1} ; \quad i=1,2, \ldots, p-2, \\
& y_{n}^{p-1}=\left(1-\beta_{n}^{p-1}\right) x_{n}+\beta_{n}^{p-1} T_{p} x_{n}, \quad n \geq 0,
\end{aligned}
$$

which is called the modified multi-step iteration process, where $\left\{\alpha_{n}\right\}_{n \geq 0},\left\{\beta_{n}^{i}\right\}_{n \geq 0} \subset[0,1]$, $i=1,2, \ldots, p-1$.

For $p=3$, we obtain the following three-step iteration process:

Algorithm 2 For a given $x_{0} \in K$, compute the sequence $\left\{x_{n}\right\}_{n \geq 0}$ by the iteration process:

$$
\begin{aligned}
& x_{n+1}=\left(1-\alpha_{n}\right) x_{n}+\alpha_{n} T_{1} y_{n}^{1}, \\
& y_{n}^{1}=\left(1-\beta_{n}^{1}\right) x_{n}+\beta_{n}^{1} T_{2} y_{n}^{2}, \\
& y_{n}^{2}=\left(1-\beta_{n}^{2}\right) x_{n}+\beta_{n}^{2} T_{3} x_{n}, \quad n \geq 0,
\end{aligned}
$$

where $\left\{\alpha_{n}\right\}_{n \geq 0},\left\{\beta_{n}^{1}\right\}_{n \geq 0}$ and $\left\{\beta_{n}^{2}\right\}_{n \geq 0}$ are three real sequences in $[0,1]$.

For $p=2$, we obtain the Ishikawa [24] iteration process:

Algorithm 3 For a given $x_{0} \in K$, compute the sequence $\left\{x_{n}\right\}_{n \geq 0}$ by the iteration process

$$
\begin{aligned}
& x_{n+1}=\left(1-\alpha_{n}\right) x_{n}+\alpha_{n} T_{1} y_{n}^{1}, \\
& y_{n}^{1}=\left(1-\beta_{n}^{1}\right) x_{n}+\beta_{n}^{1} T_{2} x_{n}, \quad n \geq 0,
\end{aligned}
$$

where $\left\{\alpha_{n}\right\}_{n \geq 0}$ and $\left\{\beta_{n}^{1}\right\}_{n \geq 0}$ are two real sequences in $[0,1]$.

If $T_{1}=T, T_{2}=I, \beta_{n}^{1}=0$ in (4.3), we obtain the Mann iteration process [14]:

Algorithm 4 For any given $x_{0} \in K$, compute the sequence $\left\{x_{n}\right\}_{n \geq 0}$ by the iteration process

$$
x_{n+1}=\left(1-\alpha_{n}\right) x_{n}+\alpha_{n} T x_{n}, \quad n \geq 0,
$$

where $\left\{\alpha_{n}\right\}$ is a real sequence in $[0,1]$.

Theorem 15 Let $K$ be a nonempty closed bounded convex subset of a smooth Banach space $X$ and $T_{1}, T_{2}, \ldots, T_{p}(p \geq 2)$ be selfmappings of $K$. Let $T_{1}$ be a continuous strictly hemicontractive mapping. Let $\left\{\alpha_{n}\right\}_{n \geq 0},\left\{\beta_{n}^{i}\right\}_{n \geq 0} \subset[0,1], i=1,2, \ldots, p-1$ be real sequences in $[0,1]$ satisfying $\sum_{n \geq 0} \alpha_{n}=\infty, \lim _{n \rightarrow \infty} \alpha_{n}=0$ and $\lim _{n \rightarrow \infty} \beta_{n}^{1}=0$. For arbitrary $x_{0} \in K$, define the sequence $\left\{x_{n}\right\}_{n \geq 0}$ by (4.1). Then $\left\{x_{n}\right\}_{n \geq 0}$ converges strongly to a point in $\bigcap_{i=1}^{p} F\left(T_{i}\right) \neq \emptyset$.

Proof By applying Corollary 13 under assumption that $T_{1}$ is continuous strictly hemicontractive mapping, we obtain Theorem 15 which proves strong convergence of the iteration 
process defined by (4.1). We will check only the condition $\lim _{n \rightarrow \infty}\left\|v_{n}-x_{n}\right\|=0$ by taking $T_{1}=T$ and $v_{n}=y_{n}^{1}$,

$$
\begin{aligned}
\left\|v_{n}-x_{n}\right\| & =\left\|y_{n}^{1}-x_{n}\right\| \\
& =\left\|\left(1-\beta_{n}^{1}\right) x_{n}+\beta_{n}^{1} T_{2} y_{n}^{2}-x_{n}\right\| \\
& =\beta_{n}^{1}\left\|T_{2} y_{n}^{2}-x_{n}\right\| \\
& \leq 2 M \beta_{n}^{1} .
\end{aligned}
$$

Now, from the condition $\lim _{n \rightarrow \infty} \beta_{n}^{1}=0$, it can be easily seen that $\lim _{n \rightarrow \infty}\left\|v_{n}-x_{n}\right\|=0$.

Corollary 16 Let $K$ be a nonempty closed bounded convex subset of a smooth Banach space $X$ and $T_{1}, T_{2}, \ldots, T_{p}(p \geq 2)$ be selfmappings of $K$. Let $T_{1}$ be a Lipschitz strictly hemicontractive mapping. Let $\left\{\alpha_{n}\right\}_{n \geq 0},\left\{\beta_{n}^{i}\right\}_{n \geq 0} \subset[0,1], i=1,2, \ldots, p-1$ be real sequences in $[0,1]$ satisfying $\sum_{n \geq 0} \alpha_{n}=\infty, \lim _{n \rightarrow \infty} \alpha_{n}=0$ and $\lim _{n \rightarrow \infty} \beta_{n}^{1}=0$. For arbitrary $x_{0} \in K$, define the sequence $\left\{x_{n}\right\}_{n \geq 0}$ by (4.1). Then $\left\{x_{n}\right\}_{n \geq 0}$ converges strongly to a point in $\bigcap_{i=1}^{p} F\left(T_{i}\right) \neq \emptyset$.

Remark 17 Similar results can be found for the iteration processes with error terms, we omit the details.

\section{Competing interests}

The authors declare that they have no competing interests.

\section{Authors' contributions}

All authors contributed equally and significantly in writing this article. All authors read and approved the final manuscript.

\section{Author details}

${ }^{1}$ Department of Mathematics, King Abdulaziz University, P.O. Box 80203, Jeddah, 21589, Saudi Arabia. ${ }^{2}$ Hajvery University, 43-52 Industrial Area, Gulberg-III, Lahore, Pakistan. ${ }^{3}$ Faculty of Mechanical Engineering, University of Belgrade, Al. Rudara 12-35, Belgrade, 11070 , Serbia.

\section{Acknowledgements}

The first author gratefully acknowledges the support from the Deanship of Scientific Research (DSR) at King Abdulaziz University (KAU) during this research. The third author gratefully acknowledges the support from the Ministry of Education and Science of Republic Serbia. The fourth author gratefully acknowledges the financial support provided by the University of Tabuk through the project of international cooperation with the University of Texas at El Paso. We are also thankful to the editor and the referees for their suggestions for the improvement of the manuscript.

Received: 9 March 2012 Accepted: 6 September 2012 Published: 24 September 2012

\section{References}

1. Chidume, CE: Iterative approximation of fixed points of Lipschitzian strictly pseudocontractive mappings. Proc. Am. Math. Soc. 99(2), 283-288 (1987)

2. Schu, J: Iterative construction of fixed points of strictly pseudocontractive mappings. Appl. Anal. 40, 67-72 (1991)

3. Park, JA: Mann iteration process for the fixed point of strictly pseudocontractive mapping in some Banach spaces. J. Korean Math. Soc. 31, 333-337 (1994)

4. Liu, Z, Kang, SM, Shim, SH: Almost stability of the Mann iteration method with errors for strictly hemicontractive operators in smooth Banach spaces. J. Korean Math. Soc. 40(1), 29-40 (2003)

5. Harder, AM, Hicks, TL: A stable iteration procedure for nonexpansive mappings. Math. Jpn. 33, 687-692 (1988)

6. Harder, AM, Hicks, TL: Stability results for fixed point iteration procedures. Math. Jpn. 33, 693-706 (1988)

7. Harder, AM: Fixed point theory and stability results for fixed point iteration procedures. Ph. D. Thesis, University of Missouri-Rolla (1987)

8. Chang, S: Some problems and results in the study of nonlinear analysis. Nonlinear Anal. TMA 30(7), 4197-4208 (1997)

9. Chang, SS, Cho, YJ, Lee, BS, Kang, SM: Iterative approximations of fixed points and solutions for strongly accretive and strongly pseudocontractive mappings in Banach spaces. J. Math. Anal. Appl. 224, 149-165 (1998)

10. Chidume, CE, Osilike, MO: Fixed point iterations for strictly hemicontractive maps in uniformly smooth Banach spaces. Numer. Funct. Anal. Optim. 15, 779-790 (1994) 
11. Ishikawa, S: Fixed points by a new iteration method. Proc. Am. Math. Soc. 44, 147-150 (1974)

12. Liu, Z, Kang, SM: Iterative approximation of fixed points for $\phi$-hemicontractive operators in arbitrary Banach spaces. Acta Sci. Math. 67, 821-831 (2001)

13. Liu, Z, Kang, SM: Stability of Ishikawa iteration methods with errors for strong pseudocontractions and nonlinear equations involving accretive operators in arbitrary real Banach spaces. Math. Comput. Model. 34, $319-330$ (2001)

14. Liu, Z, Kang, SM: Convergence theorems for $\phi$-strongly accretive and $\phi$-hemicontractive operators. J. Math. Anal. Appl. 253, 35-49 (2001)

15. Liu, Z, Kang, SM: Convergence and stability of the Ishikawa iteration procedures with errors for nonlinear equations of the $\phi$-strongly accretive type. Neural Parallel Sci. Comput. 9, 103-118 (2001)

16. Mann, WR: Mean value methods in iteration. Proc. Am. Math. Soc. 4, 506-510 (1953)

17. Agarwal, RP, Cho, YJ, Li, J, Huang, NJ: Stability of iterative procedures with errors approximating common fixed points for a couple of quasi-contractive mappings in q-uniformly smooth Banach spaces. J. Math. Anal. Appl. 272, 435-447 (2002)

18. Hussain, N, Rafiq, A, Damjanovic, B, Lazovic, R: On rate of convergence of various iterative schemes. Fixed Point Theory Appl. 2011, 45 (2011)

19. Rhoades, BE: Comments on two fixed point iteration methods. J. Math. Anal. Appl. 56, 741-750 (1976)

20. Weng, X: Fixed point iteration for local strictly pseudo-contractive mapping. Proc. Am. Math. Soc. 113(3), 727-731 (1991)

21. Xu, Y: Ishikawa and Mann iterative processes with errors for nonlinear strongly accretive operator equations. J. Math. Anal. Appl. 224, 91-101 (1998)

22. Shahzad, N, Zegeye, H: On stability results for $\phi$-strongly pseudocontractive mappings. Nonlinear Anal. TMA 64(12), 2619-2630 (2006)

23. Khan, AR, Domlo, AA, Fukhar-ud-din, H: Common fixed points of Noor iteration for a finite family of asymptotically quasi-nonexpansive mappings in Banach spaces. J. Math. Anal. Appl. 341, 1-11 (2008)

24. Hussain, N, et al.: On the rate of convergence of Kirk type iterative schemes. J. Appl. Math. 2012, Article ID 526503 (2012)

doi:10.1186/1029-242X-2012-207

Cite this article as: Hussain et al.: Almost stability of the Mann type iteration method with error term involving strictly hemicontractive mappings in smooth Banach spaces. Journal of Inequalities and Applications 2012 2012:207.

\section{Submit your manuscript to a SpringerOpen ${ }^{\circ}$ journal and benefit from:}

- Convenient online submission

Rigorous peer review

- Immediate publication on acceptance

Open access: articles freely available online

- High visibility within the field

- Retaining the copyright to your article 